\title{
Dividend Policy: An Empirical Test Using the October 1987 Crash
}

\author{
Wold Zemedkun \\ William Lewis Randolph \\ Norfolk State University \\ Norfolk, Virginia
}

The finance literature has not yet reached a consensus on the relevance of dividend policy. The main consideration in the dividend policy debate is the impact of dividends on the value of the firm's stock. Dividend policy issues have been investigated by many. Miller and Modigliani [9] analyzed the special case of perfect markets and concluded that dividend policy does not determine or affect the value of the firm. Others ([6], [8]) have argued that investors prefer dividend to capital gains, and thus dividend policy affects the valuation of the company stock. Most recent academic work leans toward the argument that dividend policy is relevant. Survey results reported by researchers ([1], [11]) indicate that corporate chief financial officers believe that dividend policy does affect stock prices. Baskin [2] analyzed dividend policy and found an inverse correlation between dividend yield and stock price volatility.

The purpose of this study is to examine the relationship between dividend policy and stock price volatility to determine if dividend yield has an impact on either stock price behavior, the rate of growth, or stock beta. ${ }^{1}$ We have chosen to observe dividend yield and stock price behavior in the period surrounding the crash of October 1987. Such a period provides us with an excellent opportunity to examine factors that affect the adjustment of prices of individual stocks to major market changes.

The primary hypothesis for this study is that stock prices of firms with high cash dividend yields are less sensitive to a market crash and exhibit lower market risk (beta) than stock prices of firms with low or no cash dividend yields. That is, the market does care about dividend policy. Dividend policy is one important firm-specific factor that could modify the effect of a crash on a firm's stock price. This is important information for investors and has implications for portfolio strategies.

The concept of duration ${ }^{2}$ is the theoretical basis for the explanation of an inverse

1The beta of a stock is a measure of its price variability companed to the variability of the stock market as indicated by an index such as the S\&P 500 index. According to the Capital Asset Pricing Model (CAPM), beta is a measure of the stock's nondiversifiable risk. As a statistical measure beta is found by regressing a stock's price changes on the market index changes over time. A stock with a high beta, greater than 1 , would be more volatile than the average stock and therefore more risky.

2Unlike maturity, which looks only at the time to the last payment from an investment, duration gives weight to the time at which each cash payment occurs. The weight assigned to each period is the present value of the cash flow for that period divided by the current price of the security. Early payments are discounted less than those received later. Thus, duration is the effective maturity of the investment. 
relationship between dividend yield and stock price volatility. As Reilly and Sidhu [10] have shown, the stock with a high dividend yield will have a shorter duration than a stock that pays no dividends. Duration considers the timing and pattern of payments to the investor and indicates stock price sensitivity to changes in yield. Thus, duration plays a vital theoretical role in the risk assessment of common stocks.

The important relationship between growth and dividend yield is also examined. Firms that retain all of their earnings need to rely less on external sources of capital during periods of high growth. The theoretical reason for firms to retain all of their earnings is to finance growth. We expect to find that firms with low dividend or zero dividend yields have a higher growth rate than firms with high dividend yields. This is important because duration is a positive function of growth rate.

\section{Data and Methodology}

The data for this study is taken from the Standard and Poor's COMPUSTAT data base. The PC PLUS version of the data base dated May 24, 1990, is used. The study period is oriented around the crash of October 1987 and the study group of stocks is drawn using three screening rules. The first screening rule is that the company's stock be listed on the New York Stock Exchange (NYSE), the American Stock Exchange (ASE), or trade in the over-the-counter market (OTC). This rule excludes Canadian stocks and companies listed only on regional exchanges. The second screening rule requires that enough data for the company be available to compute beta for September 1987. Beta is computed by using a minimum of 24 months of stock prices. The third screening rule requires a stock price greater than three dollars in September 1987. This rule is used in order to screen out "penny stocks." The National Association of Security Dealers uses a three dollar stock price minimum to qualify newer companies for inclusion in the National Market System. The application of these three screening rules to the data base results in a sample of 3,039 companies available for the study.

We divide the resulting group of stocks into three categories based upon fiscal 1987 dividend yield. Companies with a dividend yield equal to or greater than three percent are placed in the high dividend category. Companies that have a dividend yield of less than three percent but greater than zero are in the medium dividend yield category. Companies which paid no dividend in 1987 are in the zero dividend category. The three percent boundary between the high and medium dividend categories divides the companies which paid dividends into equal groups.

We form subsets of the overall study group by first separating the S\&P 500 stocks into one subset and then using listing criteria to form two more subsets. The first subset consists of companies whose stock was part of the S\&P 500 Index on September 1987. The second subset is those companies whose stock was listed on the NYSE or ASE but are not in the S\&P 500 Index. The third subset is made up of OTC companies who are not in the S\&P 500. This breakdown forms subsets of companies that are of different sizes.

We also study the monthly stock returns of the group using the period surrounding the crash as the focal point. Following the earlier empirical example of Fama, Fisher, 
Jensen, and Roll (FFJR) [5], we use the market model to investigate the effect of the crash on the stock prices of the various dividend groups. By adjusting for the market effect or systematic risk, we can focus on the pattern of excess returns or prediction errors surrounding the crash. While the FFJR methodology may have some theoretical weaknesses, it has proven to be remarkably robust in detecting abnormal stock price performance.

In order to test the hypothesis, we will employ the test statistic described in Dodd and Warner [4]. To compute the statistic, the prediction error is standardized by its estimated standard deviation. The standardized prediction error is accumulated over the prediction interval and divided by the square root of the number of time periods in this interval. The test statistic is then derived by summing the accumulated standardized prediction error across firms and dividing by the square root of the number of firms.

\section{Results}

We show various characteristics of the sample group and it's subsets by exchange listing in Tables 1 through 4 . These Tables present the mean or median of a characteristic for the sample and by high, medium, and zero dividend yield. We use the median for dividend yield and payout in order to avoid bias caused by outliers which are present in these data elements. For the other characteristics we use the mean.

In Table 1, we see that the average beta is low for the high dividend group and high for the zero dividend group. A test of the difference in the mean beta of the three dividend subgroups indicates that there is less than a one percent probability that the mean betas are equal. ${ }^{3}$ Our primary hypotheses, that risk and dividend yield are inversely related, is supported by this evidence. The correlation between dividend yield and beta is -0.24 , and, is highly significant, further confirming the inverse relationship between beta and dividend yield. In Tables 2 through 4 , we can see that the relationship between beta and dividend yield is consistent across the different listing groups.

We measure the growth rate by computing the rate of change in earnings per share (EPS), sales, and assets over the period 1983 to 1987 . A company that retains all its earnings can support a higher rate of growth without external financing. Thus, all things being equal, we could expect an inverse relationship between growth and dividend yield. This inverse relationship holds for the total sample and the subsets in at least two of the growth factors measured.

From Table 1 we can see that the zero dividend group has the highest growth rate in sales and assets but not EPS. We suspect this is because the zero dividend group contains a large proportion of relatively new companies that are at the critical point in the growth cycle and growth in earnings is taking a backseat to growth in sales and assets to support new sales.

${ }^{3}$ See Iman and Conover $[7$, p. 282] for the procedures for inferences about the difference in means. 
Table 1: Characteristics of Total Sample

\begin{tabular}{lcccc} 
& $\begin{array}{c}\text { Total } \\
\text { Sample }\end{array}$ & $\begin{array}{c}\text { High } \\
\text { Dividend* }\end{array}$ & $\begin{array}{c}\text { Medium } \\
\text { Dividend* }\end{array}$ & $\begin{array}{c}\text { Zero } \\
\text { Dividend* }\end{array}$ \\
\hline Number & 3039 & 847 & 847 & 1345 \\
Dividend Yield ** & $0.89 \%$ & $4.83 \%$ & $1.68 \%$ & $0.0 \%$ \\
Dividend Payout** & $4.8 \%$ & $54.0 \%$ & $22.2 \%$ & $0.0 \%$ \\
Beta*** & 0.99 & 0.77 & 1.02 & 1.10 \\
Growth Rates*** & & & & \\
$\quad$ EPS & $6.7 \%$ & $2.6 \%$ & $10.8 \%$ & $6.6 \%$ \\
Sales & $12.0 \%$ & $6.2 \%$ & $10.8 \%$ & $16.6 \%$ \\
$\quad$ Assets & $12.2 \%$ & $8.4 \%$ & $12.5 \%$ & $14.5 \%$ \\
Market Value & $\$ 1057$ & $\$ 1957$ & $\$ 1571$ & $\$ 179$ \\
(millions)*** & & & & \\
\hline
\end{tabular}

*High dividend stocks yield greater than $3 \%$, medium dividend stocks yield between 0 and 3\%, zero dividend stocks paid no dividend in 1987.

**The statistic computed for this characteristic is the median.

***The statistic computed for this characteristic is the average.

Table 2: Characteristics of S\&P 500 Stocks

\begin{tabular}{|c|c|c|c|c|}
\hline & $\begin{array}{c}\text { Total } \\
\text { Sample }\end{array}$ & $\begin{array}{c}\text { High } \\
\text { Dividend* }\end{array}$ & $\begin{array}{c}\text { Medium } \\
\text { Dividend* }\end{array}$ & $\begin{array}{c}\text { Zero } \\
\text { Dividend* }\end{array}$ \\
\hline$\overline{\text { Number }}$ & 456 & 195 & 211 & 50 \\
\hline Dividend Yield** & $2.58 \%$ & $4.44 \%$ & $1.88 \%$ & $0.0 \%$ \\
\hline Dividend Payout** & $32.6 \%$ & $50.2 \%$ & $25.4 \%$ & $0.0 \%$ \\
\hline Beta*** & 1.13 & 1.00 & 1.17 & 1.46 \\
\hline \multicolumn{5}{|l|}{ Growth Rates*** } \\
\hline EPS & $8.1 \%$ & $2.5 \%$ & $12.3 \%$ & $14.2 \%$ \\
\hline Sales & $7.2 \%$ & $4.2 \%$ & $9.3 \%$ & $9.5 \%$ \\
\hline Assets & $8.8 \%$ & $6.5 \%$ & $11.1 \%$ & $7.9 \%$ \\
\hline $\begin{array}{l}\text { Market Value } \\
\text { (millions)*** }\end{array}$ & $\$ 4771$ & $\$ 6204$ & $\$ 4085$ & $\$ 2168$ \\
\hline
\end{tabular}


Table 3: Characteristics of Non-S\&P 500 Listed Stocks

\begin{tabular}{lcccc}
$\begin{array}{l}\text { Total } \\
\text { Sample }\end{array}$ & $\begin{array}{c}\text { High } \\
\text { Dividend* }\end{array}$ & $\begin{array}{c}\text { Medium } \\
\text { Dividend* }\end{array}$ & $\begin{array}{c}\text { Zero } \\
\text { Dividend* }\end{array}$ & \\
\hline Number & 1284 & 417 & 388 & 479 \\
Dividend Yield** & $1.52 \%$ & $5.33 \%$ & $1.65 \%$ & $0.0 \%$ \\
Dividend Payout** & $13.8 \%$ & $58.8 \%$ & $21.3 \%$ & $0.0 \%$ \\
Beta*** & 0.97 & 0.74 & 1.02 & 1.13 \\
Growth Rates*** & & & & \\
$\quad$ EPS & $7.3 \%$ & $3.0 \%$ & $10.6 \%$ & $8.4 \%$ \\
$\quad$ Sales & $10.6 \%$ & $6.9 \%$ & $10.2 \%$ & $13.9 \%$ \\
$\quad \begin{array}{l}\text { Assets } \\
\text { Market Value }\end{array}$ & $11.9 \%$ & $9.5 \%$ & $12.2 \%$ & $13.3 \%$ \\
(millions)*** & $\$ 602$ & $\$ 889$ & $\$ 861$ & $\$ 147$ \\
\hline
\end{tabular}

*High dividend stocks yield greater than $3 \%$, medium dividend stocks yield between 0 and 3\%, zero dividend stocks paid no dividend in 1987.

**The statistic computed for this characteristic is the median.

***The statistic computed for this characteristic is the average.

\section{Table 4: Characteristics of OTC Stocks}

\begin{tabular}{lcccc} 
& $\begin{array}{c}\text { Total } \\
\text { Sample }\end{array}$ & $\begin{array}{c}\text { High } \\
\text { Dividend* }\end{array}$ & $\begin{array}{c}\text { Medium } \\
\text { Dividend* }\end{array}$ & $\begin{array}{c}\text { Zero } \\
\text { Dividend* }\end{array}$ \\
\hline Number & 1299 & 235 & 248 & 816 \\
Dividend Yield ** & $0.0 \%$ & $4.38 \%$ & $1.48 \%$ & $0.0 \%$ \\
Dividend Payout** & $0.0 \%$ & $47.1 \%$ & $20.5 \%$ & $0.0 \%$ \\
Beta*** & 0.96 & 0.63 & 0.90 & 1.06 \\
Growth Rates*** & & & & \\
$\quad$ EPS & $5.3 \%$ & $1.9 \%$ & $9.9 \%$ & $4.7 \%$ \\
$\quad$ Sales & $15.3 \%$ & $6.9 \%$ & $13.1 \%$ & $18.8 \%$ \\
$\quad \begin{array}{l}\text { Assets } \\
\text { Market Value }\end{array}$ & $13.9 \%$ & $8.2 \%$ & $14.0 \%$ & $15.7 \%$ \\
$\quad$ (millions)*** & $\$ 210$ & $\$ 323$ & $\$ 542$ & $\$ 77$ \\
\hline
\end{tabular}

*High dividend stocks yield greater than $3 \%$, medium dividend stocks yield between 0 and 3\%, zero dividend stocks paid no dividend in 1987.

**The statistic computed for this characteristic is the median.

***The statistic computed for this characteristic is the average.

Another characteristic that we measure is company size. The market value of the common stock is the surrogate we use for size. When we examine the sample by listing subset, Tables 2,3 , and 4 , we see that there is a natural breakdown by size due to the various listing requirements. The S\&P 500 companies are the largest with an average market value of $\$ 4,771$ million. The other listed stocks are next in size 
with an average of $\$ 602$ million. And, the OTC companies are the smallest with an average size of $\$ 210$ million. The size difference between the high and medium dividend groups in each subset is usually not significant, but the difference between the medium and zero dividend groups is more evident. In each subset the smallest companies are the zero dividend companies, and the difference in size between the zero dividend and the medium dividend companies is statistically significant at the $1 \%$ level.

The monthly stock returns of the study group, separated by dividend category and listing subset, are presented in Table 5. The returns for August 1987 to January 1988 are listed. The first set of returns is for the whole sample group and its categories by dividend. In October 1987, the month of the stock market crash, the total sample went down $28.2 \%(-0.282)$. The high dividend category went down $21.3 \%$, the medium dividend category down $27.4 \%$, and the zero dividend category lost $33.1 \%$. The difference between the mean returns of the different dividend categories for October 1987 is significant at the $1 \%$ level. This is more evidence confirming that high dividend yields are related to lower levels of risk.

\section{Table 5: Monthly Stock Returns: August 1987 - January 1988}

\begin{tabular}{ccccccc} 
& AUG & SEP & OCT & NOV & DEC & JAN \\
\hline Total Sample & $\mathbf{0 . 0 2 3}$ & -0.012 & -0.282 & -0.053 & 0.051 & 0.058 \\
Hi Div & 0.021 & -0.027 & -0.213 & -0.038 & 0.032 & 0.067 \\
Med Div & 0.033 & -0.011 & -0.274 & -0.043 & 0.082 & 0.035 \\
Zero Div & 0.018 & -0.003 & -0.331 & -0.068 & 0.043 & 0.068 \\
S\&P 500 & 0.027 & -0.021 & -0.254 & -0.067 & 0.090 & 0.044 \\
Hi Div & 0.027 & -0.033 & -0.224 & -0.069 & 0.060 & 0.071 \\
Med Div & 0.025 & -0.017 & -0.269 & -0.065 & 0.115 & 0.028 \\
Zero Div & $\mathbf{0 . 0 3 7}$ & 0.003 & -0.302 & -0.065 & 0.103 & 0.006 \\
Listed Stocks & $\mathbf{0 . 0 2 2}$ & -0.013 & -0.281 & -0.049 & 0.045 & 0.058 \\
Hi Div & $\mathbf{0 . 0 1 8}$ & -0.025 & -0.209 & -0.035 & 0.025 & 0.068 \\
Med Div & $\mathbf{0 . 0 3 5}$ & -0.007 & -0.286 & -0.041 & 0.077 & 0.035 \\
Zero Div & $\mathbf{0 . 0 1 5}$ & -0.007 & -0.338 & -0.068 & 0.036 & 0.070 \\
OTC Stocks & $\mathbf{0 . 0 2 3}$ & -0.008 & -0.294 & -0.052 & 0.044 & 0.064 \\
Hi Div & $\mathbf{0 . 0 2 3}$ & -0.028 & -0.212 & -0.018 & 0.024 & 0.061 \\
Med Div & $\mathbf{0 . 0 3 6}$ & -0.011 & -0.261 & -0.029 & 0.063 & 0.039 \\
Zero Div & $\mathbf{0 . 0 1 8}$ & -0.001 & -0.329 & -0.069 & 0.044 & 0.071 \\
\hline
\end{tabular}

The October returns of each of the listing subsets in Table 5 follow the same pattern with high yield stocks suffering the smallest losses in the crash and zero yield stocks suffering the highest losses. The differences between the mean returns of the various dividend categories within each listing subset are also statistically significant at the $1 \%$ level. Thus, the behavior of stock prices in the crash was consistent with their beta and the Capital Asset Pricing Model. This means that the prices of high beta stocks lost more value during the crash than the value of low beta stocks. 


\section{Conclusion}

Our analysis of companies with high, medium, and zero dividend yield in the period surrounding the stock market crash in October 1987 shows a very strong inverse relationship between risk and dividend yield. Stocks with high dividend yield have lower betas and suffered the least in the crash. Stocks that pay no dividends have significantly higher betas and suffered the greatest losses in the crash. Stocks with dividend yields between zero and three percent, the medium dividend yield group, have betas between the zero and high dividend paying stocks. The differences in the betas of these three groups is statistically significant. No significant excess returns were evident in the crash time frame.

Our examination of growth rates by dividend yield group found that the zero dividend group had the highest rate of growth in assets and sales. And the high dividend yield group had the lowest rate of growth. Growth rates of the companies under study are consistent with the theoretical view that companies that pay no dividends can support higher levels of growth.

The concept of duration is the theoretical basis for the explanation of an inverse relationship between dividend yield and stock price volatility. In general, stocks with high dividend yields have lower growth rates and therefore will have shorter durations than stocks that pay no dividends. Thus, price volatility is a direct function of duration.

The conclusion is that the market views companies that pay no dividends to be more risky and companies that pay high dividends to be less risky than companies in the medium dividend group. The market appears to be consistent (or perhaps efficient) since beta explains the post crash returns fairly well for each of the three dividend groups.

\section{References}

1. Baker, H. K., Farrely, G. E., and Edelman, R. B. "A Survey of Management Views on Dividend Policy." Financial Management (Autumn 1985), pp. 78-84.

2. Baskin, J. "Dividend Policy and the Volatility of Common Stocks." Joumal of Portfolio Management (Spring 1989), pp. 19-25.

3. Boquist, J., Racette, G., and Schlarbaum, G. "Duration and Risk Assessment for Bonds and Common Stocks." Journal of Finance, Vol. 30 (1975) pp. 1360-1365.

4. Dodd, P. and Wamer, J.B. "On Corporate Governance: A Study of Proxy Contests." Journal of Financial Economics, Vol. 11 (1983), pp. 401-38.

5. Fama, E., Fisher, L., Jensen, M., and Roll, R. "The Adjustment of Stock Prices to New Information." International Economic Review, Vol. 10 (1969), pp. 1-21.

6. Gordon, M. "Optimal Investment and Financing Policy." Joumal of Finance (1963), pp. 264-272. 
7. Iman, R. L. and Conover, W. J. Modem Business Statistics, (1983).

8. Litzenberger, R. and Ramaswamy, $K$. "The Effects of Dividends on Common Stock Prices: Tax Effects or Information Effects." Joumal of Finance, Vol. 37 (May 1982), pp. 429-443.

9. Miller, M. and Modigliani, F. "Dividend Policy, Growth and the Valuation of Shares." Journal of Business, Vol. 34 (1961), pp. 411-433.

10. Reilly, F.K. and Sidhu, R.S. "The Many Uses of Bond Duration." Financial Analysts Journal (July-August 1980), pp. 58-72.

11. Sterk, W. and Vandenberg, P. "The Market Valuation of Cash Dividends and Tax Differential Theory of Dividend Policy: A Case Revisited." The Financial Review, Vol. 25 (1990), pp. 441-455. 